\title{
Hepatic and Cerebral Energy Metabolism after Neonatal Canine Alimentation
}

\author{
R. M. KLIEGMAN, ${ }^{(46)}$ E. L. MIETTINEN, AND S. K. MORTON \\ Department of Pediatrics, Division of Pediatric Metabolism, Case Western Reserve University at Cleveland \\ Metropolitan General Hospital and Rainbow Babies and Childrens Hospital, Cleveland, Ohio, USA
}

\begin{abstract}
Summary
Intrahepatic and intracerebral metabolic responses to neonatal fasting or enteric carbohydrate alimentation were investigated among newborn dogs. Pups were either fasted or given an intravenous glucose infusion (alimented) before an enteric feeding of physiologic quantities of either glucose or galactose. These pups were also compared to another group which was completely starved throughout the study period. Gastrointestinal carbohydrate feeding resulted in enhanced hepatic glycogen content among pups after a prior state of fasting. Though there were no differences of glycogen content between glucose or galactose feeding in this previously fasted group, combined intravenous glucose and enteric galactose administration produced the greatest effect on hepatic glycogen synthesis. Intrahepatic fructose 1, 6diphosphate and phosphoenolpyruvate levels were increased among previously fasted pups fed enteric monosaccharides compared to completely starved control pups, whereas intrahepatic phosphoenolpyruvate and pyruvate levels were elevated after combined intravenous and enteric carbohydrate administration. Of greater interest was the observation that hepatic levels of ATP were significantly elevated among all groups given exogenous carbohydrates compared to the completely starved control group. In contrast to the augmented hepatic glycogen and ATP levels, there were no alterations of cerebral glycogen or ATP after alimentation. Nevertheless, cerebral pyruvate and/or phosphoenolpyruvate concentrations were elevated after enteric or combined intravenous and enteric alimentation compared to the totally starved control pups.
\end{abstract}

\section{Abbreviations}

ATP, adenosine triphosphate

Citr, citrate

FDP, fructose-1,6-diphosphate

F6P, fructose-6-phosphate

G6P, glucose-6-phosphate

P-creatine, phosphocreatine

PEP, phosphoenolpyruvate

Pyr, pyruvate

UDPG, uridinediphosphoglucose

The ability of the mammalian newborn infant to maintain adequate circulating levels of glucose and alternate fuels during starvation is attenuated compared to older infants or adults $(9,13$, $18,37)$. Blood glucose concentrations may decline more rapidly while alternate fuel provision may also be deficient as plasma free fatty acid, glycerol or ketone body concentrations fail to rise during neonatal fasting among mammals $(9,12,13,37)$. In addition, very young rats may demonstrate enhanced tissue proteolysis and survive complete nutritional deprivation for a much shorter duration than older rats $(13,14)$. In other investigations among newborn piglets, starvation was associated with a decreased basal metabolism rate as evident by diminished rates of oxygen consumption (9).

Past experience among human newborn infants has demonstrated that early alimentation prevents fasting hypoglycemia and improves neonatal survival $(1,6,43)$. Additionally, alimentation of newborn rats results in stable blood glucose concentrations and glucose production rates and also augments circulating alternate fuels levels $(11,12)$.

Rapid alterations of intrahepatic metabolic intermediates, cofactors, and regulatory enzymes are essential controlling events that permit the liver's transition from a glucose-producing organ during starvation to an organ capable of net carbohydrate uptake during alimentation $(15,33,34,38)$. This change is essential for the control of blood glucose levels, and for the replenishment of hepatic glycogen stores. During carbohydrate alimentation pyruvate becomes the predominant source of acetyl-CoA for the tricarboxylic acid cycle and may result in enhanced ATP production. The transition from fasting hepatic intermediary metabolism to that of an alimented state has been well documented among adult mammals. As there are little in vivo data describing the regulation of intrahepatic metabolism among fasted neonates, or the response of the neonatal liver to subsequent alimentation, we investigated the effects of enteric carbohydrate administration on neonatal canine hepatic glycolytic intermediates and adenine nucleotides. In addition, the effects of exogenous carbohydrate provision on cerebral energy metabolism were also investigated. As glucose and galactose are the two monosaccharides relevant to neonatal metabolism, potential differences in hepatic or cerebral metabolic regulation were also investigated after the enteric feeding of either of these two carbohydrates to newborn pups. The effects on glucose turnover, hormone levels, and glycogen metabolism are the subject of another report $(22,23)$.

\section{MATERIALS AND METHODS}

Materials. Reagents and enzymes were analytical grade and purchased from commercial sources as reported in prior reports $(26,29)$. Glucose (Mallinckrodt, St. Louis, MO) and galactose (Sigma, St. Louis, MO) were free of detectable contamination from galactose or glucose, respectively. Alkaline phosphatase for the galactose-1-phosphate assay was purchased from Sigma (St. Louis, MO).

Animals. Pregnant beagles with known delivery dates were fed a standard canine diet, and had their pups delivered at term by cesarean section as described previously. Pups were dried and kept warm in a heated, humidified incubator $(26,29)$. Catheters were then placed into the umbilical artery and vein, and the pups were returned to the incubator (23).

Experimental design. The design has been described in detail in 
a previous report (22). Briefly, glucose turnover was measured in all pups with a constant infusion of tracer quantities of $\left[6-{ }^{3} \mathrm{H}\right]-$ glucose (22). The pups were divided into three major groups after birth. The first group $(n=7)$ was completely fasted from birth until tissue sampling at $9 \mathrm{~h}$ of age. The pups in second group were infused with tracer quantities of labeled glucose as in group one, but also received an orogastric feeding of $0.625 \mathrm{~g} / \mathrm{kg}$ of either glucose $(n=7)$ or galactose $(n=7)$ at $6 \mathrm{~h}$ of age. A third group received a constant intravenous infusion of substrate quantities of glucose at $59 \mu \mathrm{mole} /(\mathrm{kg} \cdot \mathrm{min})$ in addition to the labeled tracer glucose (both commenced at $2 \mathrm{~h}$ of life). This group facilitated the investigations of enteric carbohydrate administration in a group of pups who were in a previous simulated fed state, rather than that of prior fasting. At $6 \mathrm{~h}$ of age pups from this previously "alimented" group received either a glucose $(n=6)$ or galactose $(n=8)$ feeding by orogastric tube. At $9 \mathrm{~h}$ of age tissue samples were obtained. Pups in all groups were sacrificed with a double guillotine designed to transect the cranium and abdomen, exposing cerebral cortex and liver. These tissues were immediately $(<5 \mathrm{sec})$ freeze-clamped with aluminum blocks cooled to the temperature of liquid nitrogen. Tissue was stored at $-80^{\circ} \mathrm{C}$ before extraction and analyses.

\section{ANALYSES}

Circulating substrates. Blood glucose, lactate, and plasma free fatty acids were assayed in duplicate as reported previously (26).

Tissue metabolites. Cerebral and hepatic tissue were stored at $-80^{\circ} \mathrm{C}$ until they were processed as described before $(24,29)$. Briefly, tissue was pulverized to a fine powder at the temperature of dry ice; extracted with $3 \mathrm{M}$ perchloric acid and $10 \mathrm{mM}$ EDTA; and then neutralized with $\mathrm{K}_{2} \mathrm{CO}_{3}$. Glucose, UDPG, G6P, F6P, FDP, PEP, Pyr, lactate, citrate, ATP, ADP, AMP, and phosphocreatine were assayed fluorometrically in duplicate, as reported in previous investigations of canine neonatal hepatic and cerebral metabolism $(24,29)$. Galactose-1-phosphate was determined in hepatic and cerebral tissue after acid extraction and neutralization as outlined in Bergmeyer (3).

Cytoplasmic NAD/NADH ratio was calculated (29) from:

$$
[\mathrm{NAD}] /[\mathrm{NADH}]=\text { [pyruvate] } / \mathrm{K}_{\mathrm{LDH}} \text { [lactate] }
$$

where $\mathrm{K}_{\mathrm{LDH}}=111 \times 10^{-6}$ at $\mathrm{pH} 7.0$.

Energy charge was calculated from the equation (29):

$$
\text { Energy charge }=(\mathrm{ATP}+0.5 \mathrm{ADP}) /(\mathrm{ATP}+\mathrm{ADP}+\mathrm{AMP})
$$

Statistical analyses. All notations are reported as the mean \pm S.E. Concentration of tissue intermediates are reported as $\mu \mathrm{mole} /$ $\mathrm{g}$ tissue wet weight. Standard calculator programs were used for the Student's $t$ test.

\section{RESULTS}

\section{FASTING FOLLOWED BY ENTERIC ALIMENTATION}

Circulating fuels (Table 1). Three hours after the gastrointestinal feeding of glucose, blood glucose concentrations had declined to

Table 1. Circulating fuels at the time of tissue sampling (mM)

\begin{tabular}{|c|c|c|c|}
\hline Oral Substrate & Glucose & Lactate & Free fatty acids \\
\hline None $(n=7)$ & $5.2 \pm 0.7$ & $1.6 \pm 0.2$ & $880 \pm 10$ \\
\hline Glucose $(n=7)$ & $5.8 \pm 0.8$ & $2.2 \pm 0.3^{1}$ & $2301+$ \\
\hline Galactose $(n=7)$ & $7.1 \pm 0.9^{1}$ & $1.9 \pm 0.3$ & \\
\hline
\end{tabular}
mean $\pm S . E$.

\footnotetext{
${ }^{1} p<0.05$

${ }^{2} n=6$ (three glucose, three galactose fed).

${ }^{3} P<0.001$
}

Table 2. Hepatic glycogen, glucose, and lactate concentration after fasted state $(\mu \mathrm{mole} / \mathrm{g})($ mean \pm S.E.)

\begin{tabular}{llcc}
\hline \multicolumn{1}{c}{ Oral Substrate } & Glycogen & Glucose & Lactate \\
\hline None $(n=7)$ & $430 \pm 55$ & $6.24 \pm 0.41$ & $1.70 \pm 0.22$ \\
Glucose $(n=7)$ & $664 \pm 33^{1}$ & $5.49 \pm 0.52$ & $1.89 \pm 0.34$ \\
Galactose $(n=7)$ & $588 \pm 50^{2}$ & $5.71 \pm 0.47$ & $1.65 \pm 0.21$ \\
\hline
\end{tabular}

${ }^{1} P<0.01$ compared to no substrate.

${ }^{2} P<0.05$ compared to no substrate.

the same level as that in the completely fasted pups (Table 1). In contrast, blood glucose was still elevated among pups fed galactose, when compared with the completely fasted group. Blood lactate concentrations increased after enteric glucose administration and were significantly higher $3 \mathrm{~h}$ after the feeding $(2.2 \pm 0.3)$ than at the onset of the study $(1.7 \pm 0.2),(P<0.05)$. In addition, blood lactate concentrations were also significantly higher in these pups than among completely starved pups at the time of sacrifice (Table 1). Blood lactate levels before galactose administration (1.7 $\pm 0.2)$ did not increase after the feeding $(1.9 \pm 0.3)$ as lactate levels at the conclusion of the study were equivalent to those among completely fasted pups (Table 1). Due to limited plasma available at the time of the free fatty acid analysis, the results for free fatty acids among the alimented pups were pooled. As expected, gastrointestinal carbohydrate feeding resulted in a marked reduction in free fatty acid levels.

Hepatic intermediates (Table 2) (Figs. 1 and 2). After either glucose or galactose administration, hepatic glycogen content became increased; however, there was no difference butween glycogen concentrations from pups fed glucose or galactose (Table 2 ). At the time of tissue sampling hepatic glucose and lactate concentrations were equivalent among all groups investigated (Table 2). UDPG concentrations were not affected after starvation or either hexose feeding (Fig. 1). Although G-6-P concentrations appear lower after glucose or galactose administration, these results were not significant. Of more importance was the relationship between hepatic F6P and FDP (Fig. 1). Intrahepatic F6P concentrations were not altered; however, FDP concentrations were elevated after either the glucose or galactose feeding. At the same time, PEP concentrations were also elevated among alimented pups. Although intrahepatic pyruvate values appeared increased, these changes were not significant. In addition, the calculated cytoplasmic NAD/NADH ratio was not different between these groups (758 \pm 111 , fasted; $1108 \pm 204$, glucose; and $820 \pm 198$, galactose).

After enteric carbohydrate administration, intrahepatic ATP concentrations were significantly elevated (Fig. 2). Although this elevation was more pronounced after galactose feeding, there were no differences in ATP concentrations between the alimented pups. Intrahepatic ADP and AMP concentrations were equivalent among all three groups. Although the hepatic energy charge appeared elevated in the fed groups, this did not achieve statistical significance.

Galactose-1-phosphate concentrations were determined in another series of pups investigated with an identical protocol. Intrahepatic galactose-1-phosphate was not different between pups fed glucose $(n=5)(0.070 \pm 0.019 \mu \mathrm{mole} / \mathrm{g})$ or those given galactose $(n=6)(0.054 \pm 0.034)$.

Cerebral intermediates (Tables 3 and 4). In contrast to the perturbations of hepatic glycogen, FDP, PEP, and ATP concentrations after enteric alimentation, there was no significant alterations within cerebral cortical tissue for these metabolites (Tables 3 and 4). Nevertheless, enteric feeding resulted in an increase of UDPG and pyruvate concentrations. As was observed with hepatic tissue, there were no alterations of cerebral cortical galactose-1phosphate concentrations in pups fed glucose $(n=5)(0.062 \pm$ $0.006 \mu \mathrm{mole} / \mathrm{g})$ or those given galactose $(n=5)(0.063 \pm 0.009)$. 


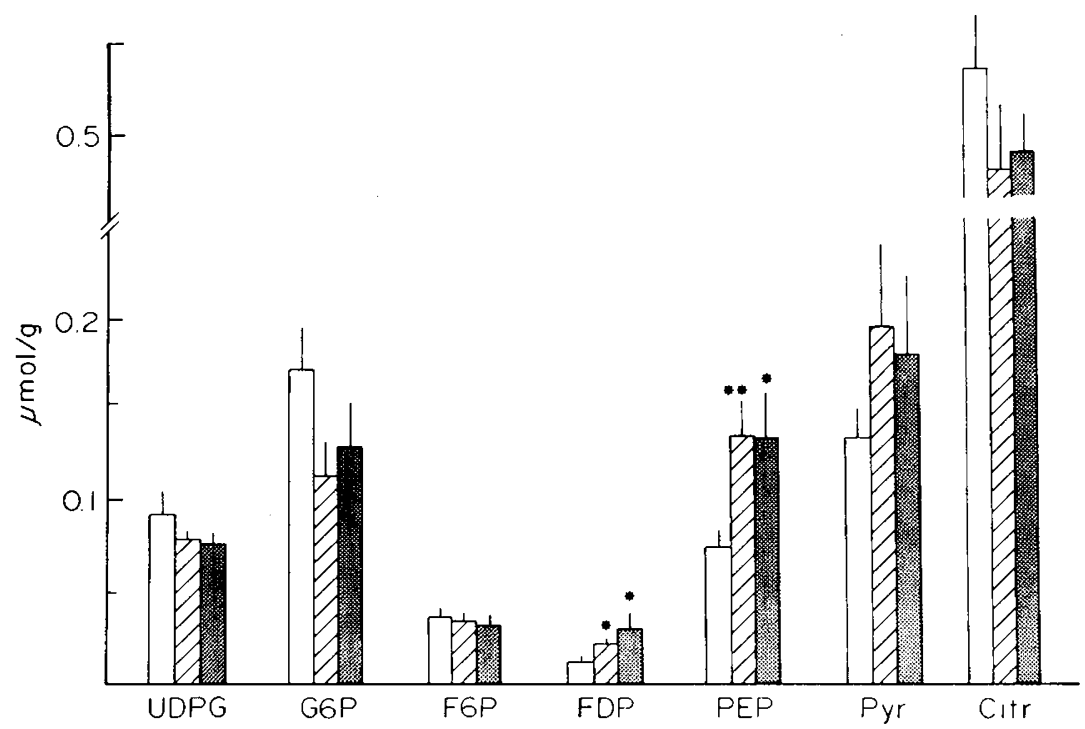

Fig. 1. Hepatic intermediates after a fasting state. $\square$, completely starved pups, $n=7$; $ש$, glucose fed, $n=7$; and $\mathbf{\square}$, galactose fed, $n=7$. Values are mean \pm S.E., in $\mu$ mole $/ g$ tissue wet weight. Definitions: UDPG, uridine- diphosphoglucose; G6P, glucose-6-phosphate; F6P, fructose-6-phosphate; FDP, fructose 1, 6-diphosphate; PEP, phosphoenolpyruvate; Pyr, pyruvate; and Citr, citrate. ${ }^{*} P<0.05$ and ${ }^{* *} P<0.02$.

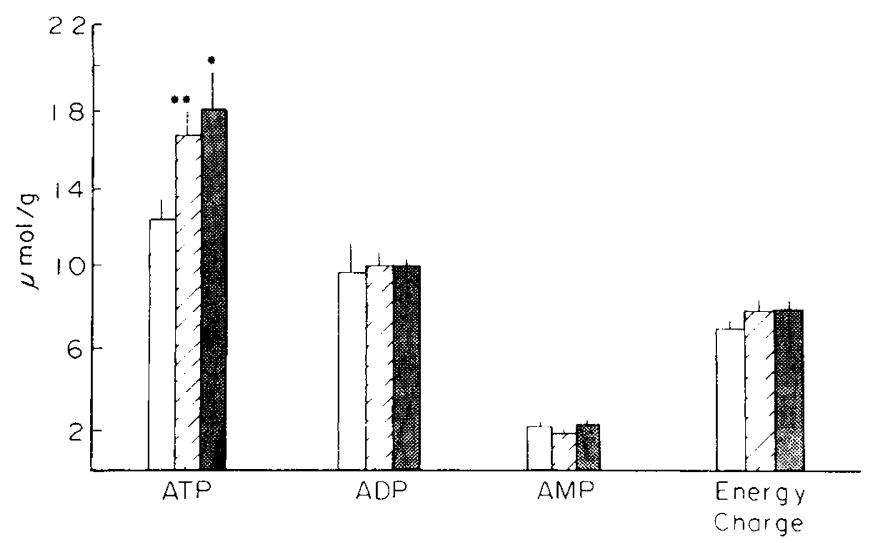

Fig. 2. Hepatic energy state after a fasting state. $\square$, completely starved pups, $n=7$; 2 , glucose fed, $n=7$; and $\mathbf{n}$, galactose fed, $n=7$. Values are mean \pm S.E. in $\mu$ mole/g. ${ }^{*} P<0.05$, and ${ }^{* *} P<0.01$.

\section{COMBINED INTRAVENOUS AND ENTERIC ALIMENTATION}

Circulating glucose and lactate (Table 5). Blood glucose concentrations at the beginning of the intravenous glucose infusion were equivalent to those of the completely fasted pups. After combined intravenous and enteric carbohydrate administration, blood glucose concentrations became elevated and were approximately three times higher than blood glucose levels among fasted pups (Table 5).

Blood lactate concentrations were equivalent to levels among fasted pups at the start of the glucose infusion among glucose (1.5 $\pm 0.2 \mathrm{mM})$ and galactose $(1.8 \pm 0.2)$ fed pups. Combined intravenous and enteric carbohydrate administration resulted in significantly higher blood lactate levels at the conclusion of the study compared to fasted pups (Table 5).

Hepatic intermediates (Table 6) (Figs. 3 and 4). After enteric carbohydrate administration combined with intravenous glucose alimentation, hepatic glycogen content was significantly greater after enteric galactose administration compared to that after glucose feeding $(P<0.05)$. As expected, hepatic glucose concentrations were elevated in the alimented groups and there was no difference between pups fed glucose or galactose.
Though hepatic UDPG concentrations appeared lower after alimentation, these were not significantly different (Fig. 3). In addition, alimentation among these groups had no effect on intrahepatic G6P, F6P or FDP concentrations (Fig. 3). In contrast, after enteric and intravenous alimentation, hepatic levels of PEP and Py were increased significantly. Intrahepatic citrate concentrations were equivalent between fasted pups and those receiving intravenous and enteric glucose administration. In contrast, citrate concentrations were unexpectedly lower among pups receiving intravenous glucose and gastrointestinal galactose alimentation (Fig. 3).

After alimentation, intrahepatic ATP concentrations increased to values $25-30 \%$ higher than that among starved pups (Fig. 4). The intrahepatic cytoplasmic redox state was similar among fasted $(758 \pm 111)$, glucose $(980 \pm 119)$, and galactose $(1101 \pm 211)$ alimented pups.

Cerebral intermediates (Tables 7 and 8). In contrast to the large increase of hepatic glycogen content, enteric and intravenous alimentation had no effect upon cerebral glycogen levels (Table 7). As expected, cerebral glucose concentrations were elevated after carbohydrate administration in a similar relationship to the elevation of blood and hepatic glucose concentrations. Cerebral UDPG levels were significantly higher after alimentation (Table 7). As observed within hepatic tissue of this group, cerebral cortical levels of PEP and Py were also elevated after carbohydrate administration.

Though the concentrations of the high energy phosphate compounds, phosphocreatine and ATP, appeared higher after alimentation, this was not statistically significant (Table 8). ADP concentrations were equivalent between those given oral glucose and the fasted pups. Pups fed galactose had elevated cerebral ADP concentrations. Nevertheless, AMP levels, the cerebral energy charge, and the cytoplasmic redox state were unaltered after carbohydrate administration (Table 8).

\section{DISCUSSION}

The mammalian newborn appears unable to maintain sufficient circulating substrate levels or to maintain normal rates of oxidative metabolism during prolonged starvation $(9,12,13,18,37)$. Compared to older subjects, newborn rats survive for a much shorter time if completely starved (14). This has been attributed to diminished adipose tissue stores but may also reflect relatively increased 
Table 3. Cerebral intermediates after fasted state $(\mu$ mole $/ g)(\text { mean } \pm \text { S.E. })^{1}$

\begin{tabular}{cccccccccc}
\hline $\begin{array}{c}\text { Oral } \\
\text { Substrate }\end{array}$ & Glycogen & Glucose & UDPG & G6P & F6P & PEP & Pyruvate & Lactate & Citrate \\
\hline $\begin{array}{c}\text { None } \\
(n=7)\end{array}$ & $2.5 \pm 0.60$ & $4.24 \pm 0.32$ & $0.034 \pm 0.014$ & $0.087 \pm 0.019$ & $0.028 \pm 0.013$ & $0.073 \pm 0.008$ & $0.170 \pm 0.019$ & $1.97 \pm 0.26$ & $0.304 \pm 0.029$ \\
$\begin{array}{c}\text { Glucose } \\
(n=7)\end{array}$ & $1.99 \pm 0.39$ & $4.02 \pm 0.55$ & $0.067 \pm 0.005^{2}$ & $0.071 \pm 0.007$ & $0.020 \pm 0.004$ & $0.113 \pm 0.024$ & $0.304 \pm 0.040^{2}$ & $2.15 \pm 0.32$ & $0.239 \pm 0.033$ \\
$\begin{array}{c}\text { Gactose } \\
(n=7)\end{array}$ & $2.34 \pm 0.66$ & $4.27 \pm 0.43$ & $0.072 \pm 0.008^{2}$ & $0.079 \pm 0.015$ & $0.027 \pm 0.004$ & $0.118 \pm 0.024$ & $0.305 \pm 0.025^{2}$ & $2.01 \pm 0.26$ & $0.276 \pm 0.041$ \\
\hline
\end{tabular}

' UDPG, uridinediphosphoglucose; G6P, glucose-6-phosphate; F6P, fructose-6-phosphate; and PEP, phosphoenolpyruvate.

${ }^{2} P<0.01$.

Table 4. Cerebral redox state and energy compounds after fasted state ( $\mu$ mole $/ g$ wet weight) (mean $\pm S . E$.

\begin{tabular}{lcccccc}
\hline \multicolumn{1}{c}{ Oral substrate } & NAD/NADH & P-Creatine & ATP & ADP & AMP & Energy charge \\
\hline None $(n=7)$ & $1265 \pm 383$ & $4.47 \pm 1.38$ & $1.73 \pm 0.133$ & $0.73 \pm 0.11$ & $0.089 \pm 0.033$ & $0.818 \pm 0.016$ \\
Glucose $(n=7)$ & $1441 \pm 266$ & $7.21 \pm 1.67$ & $2.22 \pm 0.330$ & $0.84 \pm 0.14$ & $0.139 \pm 0.021$ & $0.815 \pm 0.021$ \\
Galactose $(n=7)$ & $1690 \pm 392$ & $7.26 \pm 1.08$ & $2.04 \pm 0.190$ & $1.00 \pm 0.08$ & $0.096 \pm 0.026$ & $0.805 \pm 0.019$ \\
\hline
\end{tabular}

${ }^{1}$ Cytoplasmic.

Table 5. Blood glucose and lactate after combined alimentation $(m M)^{1}$

\begin{tabular}{lcc}
\hline Oral Substrate & Glucose & Lactate \\
\hline None $(n=7)$ & $5.2 \pm 0.7$ & $1.6 \pm 0.2$ \\
Glucose $(n=6)$ & $14.2 \pm 3.4^{2}$ & $2.6 \pm 0.3^{3}$ \\
Galactose $(n=8)$ & $16.4 \pm 2.2^{2}$ & $2.4 \pm 0.4^{4}$ \\
\hline
\end{tabular}

\footnotetext{
${ }^{1}$ Mean \pm S.E.

${ }^{2} P<0.001$

${ }^{3} P<0.01$

${ }^{4} P<0.05$
}

Table 6. Hepatic glycogen, glucose, and lactate concentrations after combined alimentation $(\mu \mathrm{mole} / \mathrm{g})^{1}$

\begin{tabular}{lllc}
\hline \multicolumn{1}{c}{ Oral substrate } & Glycogen & Glucose & Lactate \\
\hline None $(n=7)$ & $430 \pm 55$ & $6.24 \pm 0.41$ & $1.70 \pm 0.22$ \\
Glucose $(n=6)$ & $724 \pm 35^{2}$ & $9.92 \pm 1.21^{3}$ & $2.37 \pm 0.41$ \\
Galactose $(n=8)$ & $811 \pm 33^{2}$ & $8.83 \pm 0.70^{3}$ & $2.10 \pm 0.13$ \\
\hline
\end{tabular}

\footnotetext{
'Mean \pm S.E.

${ }^{2} P<0.01$

${ }^{3} P<0.001$
}

energy requirements as noted by higher rates of oxygen consumption observed among newborn mammals as compared with adults of the same species (7). In contrast to the older animals, blood glucose concentration in the newborn rat declines more rapidly during fasting, whereas starvation from birth results in diminished circulating levels of glucose, glycerol, free fatty acids, ketones, and triglycerides (12). Assuming that diminished circulating levels of these fuels represent an attenuated provision of oxidizable substrates, oxygen consumption and subsequent energy production during neonatal fasting should be diminished. When measured among fasted newborn piglets oxygen consumption declines during starvation (9). Similarly, human neonates have lower rates of oxygen consumption when they are fasted, compared to infants after the initiation of alimentation (4).

Twenty-four hours of fasting during the first day of life among normal newborn dogs resulted in stable circulating levels of glucose, ketone bodies, alanine, and lactate $(20,25)$. Steady state glucose production rates remained unchanged in these fasting newborn dogs from $3-24 \mathrm{~h}$ of age $(20,25)$. Free fatty acid concentrations, palmitate turnover and oxygen consumption, however, declined by $24 \mathrm{~h}$ of neonatal canine fasting (Kliegman unpublished data). As evident in the present investigation, the initiation of carbohydrate alimentation had resulted in significant alterations of circulating fuels, hepatic intermediates, and ATP concentrations when compared to completely starved control newborn dogs.

Hepatic metabolism. When carbohydrates are administered to previously fasted animals, the concentration of key regulatory hepatic intermediates may change rapidly. In our pups, the glycemic response after enteric carbohydrates persisted for $3 \mathrm{~h}$. Although a delay of tissue sampling after carbohydrate administration may not depict the immediate intrahepatic metabolic events, significant alterations of hepatic intermediates and high energy phosphate compounds were observed $3 \mathrm{~h}$ after alimentation was given.

The effects of carbohydrate administration on hepatic glycogen metabolism was discussed in another report (22). As reported in that part of the investigation, hepatic glycogen content was significantly enhanced $3 \mathrm{~h}$ after an enteric feeding of either carbohydrate. Hepatic canine glycogen content declined progressively during $24 \mathrm{~h}$ of neonatal fasting (29). As fasted pups had lower hepatic glycogen levels at $9 \mathrm{~h}$ of age than at birth, the elevated glycogen content among alimented pups may represent a state of net glycogen synthesis rather than that of the sustained glycogenolysis observed among completely starved pups.

Hepatic concentrations of FDP were elevated after carbohydrate administration to pups who were in a prior fasting state. Similar observations have been reported in hepatic tissue from alimented adult rats, and within human ascites cells in tissue culture exposed to high glucose concentrations $(8,15)$. These data would suggest that neonatal enteric carbohydrate alimentation after a period of starvation resulted in enhanced glycolytic activity through phosphofructokinase. Increased activity of phosphofructokinase would result in higher concentrations of this regulatory enzymes product, FDP $(30,40)$. Alternatively, the lower levels of FDP observed among the completely starved pups may suggest that gluconeogenesis was more active among these starved newborn dogs. Enhanced activity of the gluconeogenic enzyme, fructose-diphosphatase, may diminish its substrate's concentration (FDP) as the net flow through this gluconeogenic pathway increases toward hepatic glucose production. Gluconeogenesis from lactate was observed after $9 \mathrm{~h}$ of neonatal canine starvation and contributed to approximately $10 \%$ of fasting systemic glucose production $(20,25)$. Increased concentrations of hepatic FDP among fed pups suggest that gluconeogenesis may be diminished after hexose administration and/or that glycolytic activity may be enhanced at the level of the F6P, FDP regulatory cycle (40).

Glucose and galactose feeding also increased intrahepatic concentrations of PEP. Similar observations had been reported after the addition of glucose to human tissue culture cells, whereas hepatic PEP concentrations declined during starvation among adult rats $(15,17)$. Hepatic PEP concentrations may be determined 


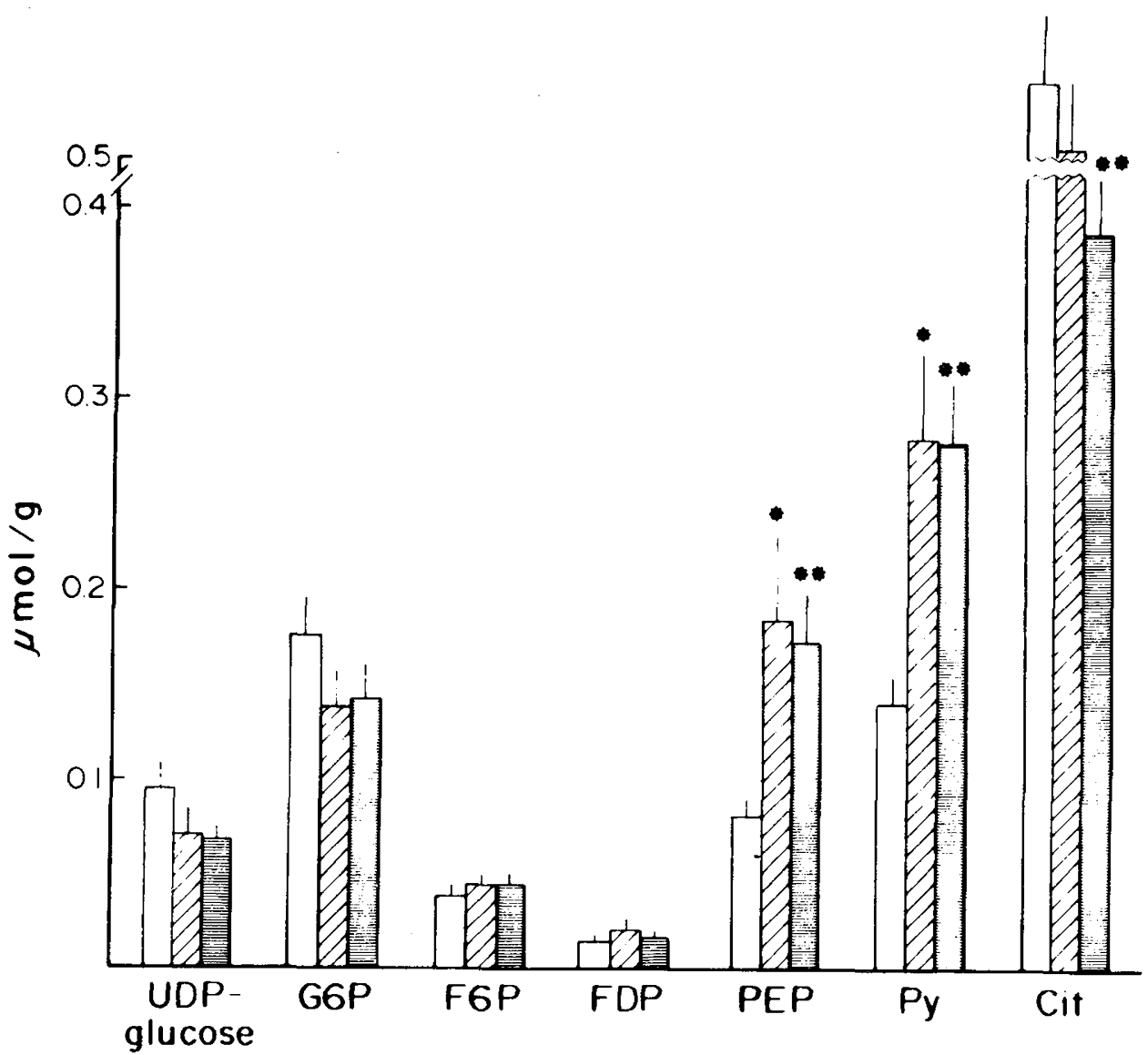

Fig. 3. Hepatic intermediates after combined intravenous and enteric feeding. $\square$, completely starved pups, $n=7$; $\mathbb{Z}$, intravenous and enteric glucose, $n=6$; and $\boldsymbol{n}$ intravenous and enteric galactose, $n=8$. Notations and abbreviations are as in Figure $1 .{ }^{*} P<0.05$ and ${ }^{* *} P<0.01$.

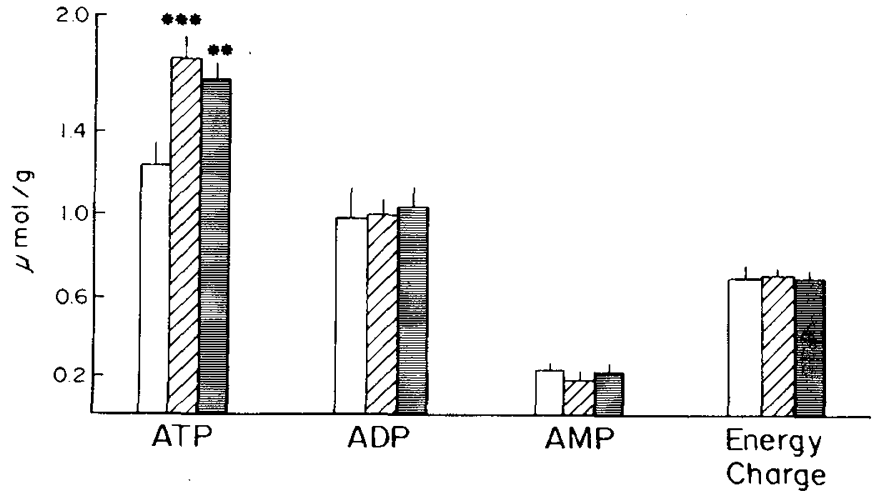

Fig. 4. Hepatic energy state after combined alimentation. $\square$, com-

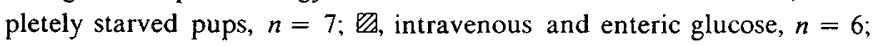
and $\boldsymbol{\square}$, intravenous glucose and enteric galactose, $n=8 .{ }^{* *} P<0.01$ and $* * * P<0.001$

by substrate cycling through pyruvate and back again to PEP through oxaloacetic acid $(31,32)$. The rate of this cycling increased during alimentation and may explain in part the enhanced concentrations of PEP $(8,31)$. Control regulated at the level of the pyruvate kinase may also alter PEP concentrations (5). Of the potential cofactors or allosteric regulators involved, enhanced intrahepatic levels of ATP may inhibit this enzyme's activity, which may result in the raised PEP concentrations observed in the fed pups (27).

Fasting lowered adult and fetal murine hepatic pyruvate concentrations and this may be related to diminished net glycolysis or the requirement of pyruvate carbons for gluconeogenesis through the pathways involving phosphoenolpyruvate carboxykinase and pyruvate carboxylase $(10,15,35,42)$. Carbohydrate refeeding of fasted adult rats resulted in enhanced hepatic pyruvate concentrations (41). Regulation of glycolysis by augmented hepatic ATP concentrations observed during combined intravenous and enteric alimentation may inhibit pyruvate dehydrogenase activity and result in accumulation of pyruvate (39).

The most significant observation, however, was the elevation of intrahepatic ATP levels, which were persistent $3 \mathrm{~h}$ after carbohydrate alimentation in all alimented groups. Fasting lowered adult and fetal murine hepatic ATP levels, whereas refeeding enhanced hepatic ATP concentrations among adults of this species $(10,15$, $35,41)$. Whether the alimented associated increase of hepatic ATP levels was due to diminished utilization or enhanced production had not been determined. It may be possible that during fasting the neonatal liver was not provided with ample fuels to support hepatic oxidative metabolism, and subsequent ATP production. After alimentation the provision of an exogenous source of substrate may have corrected this deficit. The enhanced oxygen consumption after feeding among previously fasted newborn human infants may support the conclusion that ATP production may be diminished during fasting (4). An alternate possibility is that hepatic ATP utilization had increased during starvation and resulted in lower levels of this high energy phosphate compound. Hepatic ATP concentrations were lower during gluconeogenesis associated with starvation among adult rats $(15,35)$. As gluconeogenic activity was present among newborn dogs completely starved for $9 \mathrm{~h}$, ATP may be utilized for this energy consuming process. Because neonatal canine oxygen consumption declines during starvation, the diminished hepatic concentrations of ATP suggest that hepatic energy production may have been attenuated. 
Table 7. Cerebral intermediates after combined alimentation ( $\mu$ mole $/ g$ ) mean $\pm S . E^{1}$

\begin{tabular}{|c|c|c|c|c|c|c|c|c|c|}
\hline $\begin{array}{c}\text { Oral } \\
\text { substrate }\end{array}$ & Glycogen & UDPG & Glucose & G6P & F6P & PEP & Pyruvate & Lactate & Citrate \\
\hline $\begin{array}{l}\text { None } \\
\qquad(n=7)\end{array}$ & $2.50 \pm 0.60$ & $0.034 \pm 0.014$ & $4.24 \pm 0.32$ & $0.087 \pm 0.019$ & $0.028 \pm 0.013$ & $0.073 \pm 0.008$ & $0.170 \pm 0.019$ & $1.97 \pm 0.26$ & $0.304 \pm 0.029$ \\
\hline $\begin{array}{l}\text { Glucose } \\
\qquad(n=6)\end{array}$ & $2.24 \pm 0.47$ & $0.093 \pm 0.009^{2}$ & $7.05 \pm 0.76^{2}$ & $0.083 \pm 0.015$ & $0.036 \pm 0.007$ & $0.162 \pm 0.021^{3}$ & $0.277 \pm 0.023^{3}$ & $2.40 \pm 0.50$ & $0.284 \pm 0.029$ \\
\hline $\begin{array}{l}\text { Galactose } \\
(n=8)\end{array}$ & $2.95 \pm 0.50$ & $0.077 \pm 0.008^{2}$ & $6.68 \pm 0.54^{2}$ & $0.079 \pm 0.006$ & $0.025 \pm 0.003$ & $0.159 \pm 0.023^{2}$ & $0.360 \pm 0.036^{3}$ & $2.21 \pm 0.26$ & $0.294 \pm 0.023$ \\
\hline
\end{tabular}

${ }^{1}$ UDPG, uridinediphosphoglucose; G6P, glucose-6-phosphate; F6P, fructose-6-phosphate; and PEP, phosphoenolpyruvate.

${ }^{2} P<0.01$

${ }^{3} P<0.001$

Table 8. Cerebral redox state and high energy phosphate compounds after combined alimentation ( $\mu$ mole/g wet weight) (mean $\pm S . E$.)

\begin{tabular}{lcccccc}
\hline \multicolumn{1}{c}{ Oral substrate } & $\begin{array}{c}\text { Cytoplasmic } \\
\text { NAD/NADH }\end{array}$ & P-Creatine & ATP & ADP & AMP & Energy charge \\
\hline None $(n=7)$ & $1265 \pm 383$ & $4.47 \pm 1.38$ & $1.73 \pm 0.133$ & $0.73 \pm 0.11$ & $0.089 \pm 0.033$ & $0.818 \pm 0.019$ \\
Glucose $(n=6)$ & $1371 \pm 302$ & $6.88 \pm 0.71$ & $1.90 \pm 0.180$ & $0.86 \pm 0.09$ & $0.097 \pm 0.017$ & $0.817 \pm 0.016$ \\
Galactose $(n=8)$ & $1423 \pm 294$ & $8.85 \pm 1.50$ & $2.02 \pm 0.141$ & $1.05 \pm 0.03^{1}$ & $0.126 \pm 0.018$ & $0.816 \pm 0.017$ \\
\hline
\end{tabular}

${ }^{1} P<0.01$

Cerebral metabolism. In contrast to the significant enhancement of hepatic glycogen content and the elevations of hepatic ATP concentrations, cerebral glycogen and ATP levels were unaltered after carbohydrate administration. In previous investigations it was observed at $9 \mathrm{~h}$ of age that systemic glucose production among fasted pups varies between $20-40 \mu \mathrm{mole} /(\mathrm{kg} \cdot \mathrm{min})(20,22,23,25)$. As ketone body concentrations were very low during this time period, neonatal canine cerebral energy metabolism may depend predominantly upon cerebral glucose oxidation (16). The observation that cerebral ATP and glycogen content were unperturbed after the administration of exogenous carbohydrates suggests that fasting rates of systemic glucose production were sufficient for the oxidative requirements of the newborn canine brain. In support of this conclusion cerebral cortical levels of ATP remained constant during $24 \mathrm{~h}$ of neonatal canine fasting and were equivalent to the concentrations reported here among alimented pups (21, 24).

In parallel to the elevated hepatic PEP and Pyr concentrations among pups receiving combined intravenous and enteric alimentation, cerebral cortical tissue also demonstrated elevated levels of these intermediates. There is a paucity of data that describes the effects of alimentation on cerebral cortical glycolytic intermediates among adults or neonates. It is known however that fetal and neonatal cerebral glucose uptake is related to circulating glucose levels $(19,28)$. It was therefore possible that increased provision of glucose to the brain and subsequent enhanced cerebral glucose utilization and glycolysis had resulted in the intermediate alterations reported here. Similar regulatory controls on hepatic as well as cerebral pyruvate kinase and pyruvate dehydrogenase may be the mechanism responsible for these intermediate changes $(2,36)$.

The alterations of intrahepatic intermediates and ATP concentrations after either glucose or galactose administration suggested that hepatic energy production and glycogen synthesis had been enhanced. In contrast, cerebral glycogen and ATP concentrations were unaltered. Under these circumstances, cerebral high energy compounds were unaffected but enhanced glycolytic activity may have resulted in diversion of glucose derived carbons into pathways for tissue synthesis rather than for energy production.

\section{REFERENCES AND NOTES}

1. Auld, P. A. M., Bhangananda, P., and Mehta, S.: The influence of an early caloric intake with I-V glucose on catabolism of premature infants. Pediatrics, 37: 592 (1966)

2. Bennett, M. J., Timperley, W. R., Taylor, C. B., and Hill, A. A.: The development of glycolytic and pentose phosphate shunt enzymes in human brain. Biol. Neonate, 31: 173 (1977)

3. Bergmeyer, H. U.: Methods of enzymatic analysis. New York: Academic, 3-4: 1404-1890 (1974)
4. Bhakoo, O. N and Scopes, J. W. Minimal rates of oxygen consumption in smallfor-dates babies during the first week of life. Arch. Dis. Child., 49: 583 (1974). 5. Blair, J. B., Cimbala, M. A., Foster, J. L., and Morgan, R. A.: Hepatic Pyruvate Kinase: regulation by glucagon, cyclic adenosine $3^{\prime}: 5^{\prime}$-monophosphate, and insulin in the perfused rat liver. J. Biol. Chem., 251: 3756 (1976).

6. Cornblath, M., Forbes, A. E., Pildes, R. S., Luebben, G., and Greengard, J.: A controlled study of early fluid administration on survival of low birth weight infants. Pediatrics, 38: 547 (1966).

7. Dawes, G. S.: In: Foetal and Neonatal Physiology. Yearbook Pub. Chicago, 1979, pp. 191-209.

8. Friedmann, B., Goodman, E. H., Jr., Saunders, H. L., Kostos, V., and Weinhouse, S.: An estimation of pyruvate recycling during gluconeogenesis in the perfused rat liver. Archives of Biochem. Biophys., 143: 566 (1971).

9. Gentz, J., Bengtsson, G., Hakkarainen, J., Hellstrom, R., and Persson, B.: Metabolic effects of starvation during neonatal period in the piglet. Am. $\mathbf{J}$. Physiol., 218(3): 662 (1970).

10. Girard, J. R., Ferre, P., Gilbert, M., Kervran, A., Assan, R., and Marliss, E. B. Fetal metabolic response to maternal fasting in the rat. Am. J. Physiol., 232(5): E456 (1977).

11. Girard, J. R. and Guillet, I.: Glucose turnover rate in newborn rats. Biochem. J., 148: 345 (1975)

12. Girard, J. R., Guillet, I., Marty, J., and Marliss, E. B.: Plasma amino acid levels and development of hepatic gluconeogenesis in the newborn rat. Am. J. Physiol., 229(2): 466 (1975).

13. Goodman, M. N., Reed Larsen, P., Kaplan, M. M., Aoki, T. T., Young, V. R. and Ruderman, N. B.: Starvation in the rat. II. Effect of age and obesity on protein sparing and fuel metabolism. Am. J. Physiol., 239 (Endocrinol. Metab. 2): $\mathrm{E} 277$ (1980).

14. Goodman, M. N. and Ruderman, N. B.: Starvation in the rat. I. Effect of age and obesity on organ weights, RNA, DNA, and protein. Am. J. Physiol., 239 (Endocrinol. Metab. 2): E269 (1980)

15. Greenbaum, A. L., Gumaa, K. A., and McLean, P.: The distribution of hepatic metabolites and the control of the pathways of carbohydrate metabolism in animals of different dietary and hormonal status. Archives Biochem. Biophys. 143: 617 (1971)

16. Gregoire, N. M., Gjedde, A., Plum, F., and Duffy, T. E.: Cerebral blood flow and cerebral metabolic rates for oxygen, glucose, and ketone bodies in newborn dogs. J. Neurochem., 30: 63 (1978).

17. Gumaa, K. A. and McLean, P.: The pentose phosphate pathway of glucose metabolism: Enzyme profiles and transient and steady-state content of intermediates of alternative pathways of glucose metabolism in krebs ascites cells. Biochem. J., 115: 1009 (1969).

18. Heird, W. C., Driscoll, J. M., Jr., Schullinger, J. N., Grebin, B., and Winters, R W.: Intravenous alimentation in pediatric patients. J. Pediatr., 80: 351 (1972)

19. Hernandex, M. J., Vannucci, R. C., Salcedo, A., and Brennan, R. W.: Cerebral blood flow and metabolism during hypoglycemia in newborn dogs. J. Neurochem., 35: 622 (1980).

20. Kliegman, R. M., Rahiala, E. L., and Adam, P.: Effect of maternal canine starvation on fetal and neonatal substrates and neonatal glucose production Pediatr. Res., 13: 477 (1979).

21. Kliegman, R. M., Rahiala, E. L., and Adam, P. A. J.: Effect of maternal canine starvation on fetal and neonatal cerebral metabolism. Pediatr. Res., 13: 477 (1979).

22. Kliegman, R. M., Miettinen, E. L., Kalhan, S. C., and Adam, P. A. J.: Effect of enteric galactose on neonatal canine carbohydrate metabolism. Metabolism, 30: 1109 (1981).

23. Kliegman, R. M., Miettinen, E. L., and Adam, P. A. J.: Effect of oral galactose on neonatal canine glucose utilization. Pediatr. Res., 14: 576 (1980). 
24. Kliegman, R. M., Miettinen, E. L., Rolin, W., and Adam, P. A. J.: Effect of maternal canine starvation on neonatal cerebral metabolism. Pediatr. Res., 15 : 859 (1981).

25. Kliegman, R. M., Miettinen, E. L., and Adam, P. A. J.: Fetal and neonatal responses to maternal canine starvation: Circulating fuels and neonatal glucose production. Pediatr. Res., 15: 945 (1981).

26. Kliegman, R. M., Miettinen, E. L., and Adam, P. A. J.: Substrate-turnover interrelationships in fasting neonatal dogs. Am. J. Physiol., 239 (Endocrinol. Metab. 2): E287 (1980).

27. Llorente, P., Marco, R., and Sols, A.: Regulation of liver pyruvate kinase and the phosphoenolpyruvate crossroads. Eur. J. Biochem., 13: 45 (1970).

28. Mann, L. I., Duchin, S., Halverstram, J., Mastrantonio, J., Weiss, R., and Schulman, J.: The effect of hypoglycemia on fetal brain function and metabolism. Amer. J. Obs. Gynecol., 117: 45 (1973).

29. Miettinen, E. L.: Effect of maternal canine starvation on fetal and neonatal liver metabolism. Am. J. Physiol., 240 (Endocrinol. Metab. 3): E88 (1981).

30. Nieto, A. and Castano, J. G.: Control in vivo of rat liver phosphofructokinase by glucagon and nutritional changes. Biochem. J., 186: 953 (1980).

31. Ottaway, J. H. and Mowbray, J.: The role of compartmentation in the control of glycolysis. In: B. L. Horecker and E. R. Stadman, Ed.: Current Cell Topics in Cell Regulation, Volume 12, pp. 108-209 (Academic Press, New York, 1977).

32. Rognstad, R.: Cyclic AMP induced inhibition of pyruvate kinase flux in the intact liver cell. Biochem. Biophys. Res. Comm., 63: 900 (1975)

33. Seitz, H. J., Muller, M. J., Krone, W. and Tarnowski, W.: Rapid conversion by insulin of hepatic intermediary metabolism from glucose production to glucose utilization in the liver of Alloxan-diabetic rats. Diabetes, 26: 1159 (1977).

34. Stalmans, W: The role of the liver in the homeostasis of blood glucose. In: B. L. Horecker and E. R. Stadtman, Eds.: Current topics in Cell Regulation, Vol. 11, pp. 51-98 (Academic Press, New York, 1976).

35. Start, C. and Newsholme, E. A.: The effects of starvation and Alloxan-diabetes on the contents of citrate and other metabolic intermediates in rat liver. Biochem. J., 107: 411 (1968)

36. Stum.pf, B. and Kraus, H.: Regulatory aspects of glucose and ketone body metabolism in infant rat brain. Pediatr. Res., 13: 585 (1979)

37. Swiatek, K. R., Kipnis, D. M., Mason, G., Chao, K., and Cronblath, M.:

Copyright $(C) 1983$ International Pediatric Research Foundation, Inc. $0031-3998 / 83 / 1704-0000 \$ 02.00 / 0$
Starvation in hypoglycemia in newborn pigs. Am. J. Physiol., 214(2): 400 (1968)

38. Taunton, O. D., Stifel, F. B, Greene, H. L., and Herman, R. H. Rapid reciproca changes in rat hepatic glycolytic enzyme and fructose diphosphatase activities following insulin and glucagon injection. J. Biol. Chem., 249: 7228 (1974).

39. Taylor, S. I., Mukherjee, C., and Jungas, R. L.: Regulation of pyruvate dehydro genase in isolated rat liver mitochondria. J. Biol. Chem., 250: 2028 (1975).

40. Underwood, A. H. and Newsholme, E. A.: Properties of Phosphofructokinase from rat liver and their relation to the control of glycolysis and gluconeogenesis. Biochem. J., 95: 868 (1965)

41. Veech, R. L., Raijman, L., and Krebs, H. A.: Equilibrium relations between the cytoplasmic adenine nucleotide system and nicotinamide-adenine nucleotide system in rat liver. Biochem. J., 1I7: 499 (1970).

42. Williamson, D. H., Lund, P., and Krebs, H. A.: The redox state of free nicotinamide-adenine dinucleotide in the cytoplasm and mitochondria of rat liver. Biochem. J., 103: 514 (1967).

43. Wu, P. Y. K., Teilmann, P., Gabler, M., Vaughan, M., and Metcoff, J.: "Early" versus "Late" feeding of two birth weight neonates: Effect on serum bilirubin, blood sugar, and responses to glucagon and epinephrine tolerance tests. Pediatrics 39: 733 (1967).

44. The authors would like to express their appreciation to Mr. G. Campbell, Ms. W. Rolin, and Ms. A. Sutton for their technical assistance and to Dr. Sherman Sachs of the Department of Veterinary Medicine of Case Western Reserve University for surgical and general care of the Beagles. We also express our gratitude to Ms. Sandra Hartman for her patience and professional preparation of this text. This work was supported by Grants \#168-78 and 4(1) RIA-79 of the Diabetes Association of Greater Cleveland and from Grant \#HD05740 of the NICHHD.

45. Dr. R. M. Kliegman is a recipient of Research Investigation Award from the Diabetes Association of Greater Cleveland.

46. Requests for reprints should be addressed to: Dr. R.M. Kliegman, Department of Pediatrics, Cleveland Metropolitan General Hospital, 3395 Scranton Road Cleveland, Ohio 44109

47. Received for publication March 23, 1982.

48. Accepted for publication September 1, 1982.

Printed in U.S.A. 